\title{
Trauma Systems Therapy in Residential Settings: Improving Emotion Regulation and the Social Environment of Traumatized Children and Youth in Congregate Care
}

\author{
Adam D. Brown • Kelly McCauley • Carryl P. Navalta • \\ Glenn N. Saxe \\ Published online: 11 September 2013 \\ (C) The Author(s) 2013. This article is published with open access at Springerlink.com
}

\begin{abstract}
Although abundant evidence exists indicating the prevalence of trauma exposure among youth in residential care, few models exist for creating trauma-informed milieu treatment. This article outlines the problem and describes the implementation of Trauma Systems Therapy (TST) in three residential centers. TST is unique in emphasizing youth emotions and behaviors as well as the role a distressed or threatening social environment may play in keeping a traumatized youth in a dysregulated state. This dual emphasis makes TST specifically appropriate to implementation in congregate care, focusing assessment and intervention strategies on both clinical treatment and the functioning of the therapeutic milieu itself. Data are reported on incidents of the use of physical restraint; numbers of disrupted foster care placements following discharge from residential treatment; and scores on psychometric measures of children's functioning and emotion regulation capacity. Knowledge gained through TST implementation in these three residential centers has important implications for developing a model of trauma-informed congregate care.
\end{abstract}

Keywords Trauma $\cdot$ Residential treatment $\cdot$ Milieu $\cdot$ Trauma systems therapy

The treatment of youth in congregate care dates back to the 17 th century when youth were housed in homes for the poor and

A. D. Brown $(\bowtie) \cdot$ G. N. Saxe

NYU Langone Medical Center, Child Study Center, 1 Park Avenue, New York, NY 10016, USA

e-mail: Adam.brown2@nyumc.org

K. McCauley

KVC Health Systems, 1202 E. 23rd St., Ste. C Lawrence, KS 66046, USA

\section{P. Navalta}

Division of Graduate Medical Sciences, BU School of Medicine, 72 East Concord Street, Robinson Building, Suite B-2903, Boston, MA 02118-2526, USA parentless (Mayer et al. 1978). The orphanage model shifted toward the end of the 19th century, with the rise of the more current model of the Residential Treatment Center (RTC). The RTC model views these youth as not merely requiring shelter and supervision, but rather as emotionally and behaviorally disturbed youngsters in need of treatment (Noshpitz 1962).

The nature and specifics of such treatment, however, has varied widely. In fact, treatment in an RTC setting has been described as a "black box" (Coen et al. 2003), with little documented about the nature and outcome of interventions. Although various approaches to treatment, most involving the role of the "therapeutic milieu" have existed, it is only recently that such approaches have begun to comprehensively and systematically address the complex needs of the youth that tend to inhabit these residential centers. While youth in residential settings do present with a varied array of behaviors and backgrounds, there are clear common denominators. The clearest commonalities are the degree to which these youth engage in behaviors that defy societal norms, and create risk to themselves and others. Less obvious, though of critical significance, is the increasing degree to which these youth have experienced interpersonal trauma (Bloom 2005; Zelechoski et al., 2013).

A study of 142 youth in residential treatment found very high levels of exposure to potentially traumatic experiences, with $47 \%$ having been exposed to sexual abuse, $63 \%$ with exposure to physical abuse, and $69 \%$ with significant histories of neglect (Hussey and Guo 2002). A recent study found that youth in residential treatment had higher rates of exposure to multiple types of traumatic events, as well as more significant functional impairment (Briggs et al. 2012).

In recent years, a number of models for treating traumatized youth have been utilized in residential settings (Knoverek et al. 2013; Zelechoski et al. 2013). Trauma-informed interventions in residential settings have tended to focus either on treating emotion and behavior dysregulation (see, for example, Habib et al. 2013), or on teaching staff theoretical principles of the impact of trauma in order to create a trauma-informed milieu (Rivard et al. 
2003). A recent exception is the Attachment, Regulation and Competency (ARC) model, which adopts a systems-level approach to addressing the regulatory capacities of complexly traumatized youth in residential treatment settings (Hodgdon et al. 2013). Little data exists, however, on the efficacy of trauma-informed interventions in residential treatment, both because of the paucity of such interventions, as well as the fact that it is challenging to implement a randomized controlled clinical trial in settings with high client and staff turnover and short lengths of stay. The promising use of non-experimental or quasi-experimental research designs, however, may allow for the efficacy of such interventions to be meaningfully evaluated (Ford and Hawke 2012).

As Bloom and Farragher (2010) point out, programs serving a population with such complex needs require a focus on more than just the individual level of the youth. An emphasis on systems culture change at the organizational level is required to effect meaningful and lasting change. Thus, the present paper provides an overview of the successful adaptation and implementation of a trauma-informed, systems oriented, empirically-supported treatment model: Trauma Systems Therapy (TST), at three residential facilities.

\section{What is TST?}

TST is both a clinical model for the treatment of child traumatic stress as well as an organizational model that provides a framework for the coordinated provision of appropriate services. We provide a brief overview of this treatment model. A full description of the principles and practice of TST are beyond the scope of this article and may be found in the published manual (Saxe et al. 2007). Briefly, the primary clinical innovation that encapsulates TST is the concept of the trauma system. Bound exclusively by a traumatized child's emotion regulation capacity and his/her social environment (which can also include the system of care), the trauma system is defined as follows:

- A traumatized child who has difficulty regulating emotional states; and

- A social environment and/or system of care that is not able to help the child regulate these emotional states.

An accurate assessment of the trauma system is thus imperative. In parallel with the definition, the evaluation of the trauma system consists of two facets: 1) assessing a youth's emotion regulation capacity; and 2) assessing the functioning of the social environment in which the youth lives. This dual assessment determines the treatment phase that, in turn, determines the most appropriate course of treatment. Treatment modalities are designed to help the youth become better regulated as well as to help stabilize the social environment that is contributing to this dysregulation. Moreover, this assessment is repeated frequently to accurately assess the youth's current phase of treatment as well as to monitor progress and need. A psychometric tool was developed to help gather the necessary information for this ongoing evaluation (Child Ecology Check In [CECI]; Appendix A).

A second key innovation of TST is that the clinical model is embedded in an organizational model. That is, TST describes not only what is done clinically, but also how to integrate and orchestrate different clinical interventions so that children receive the right level of care, at the right moment in time, and in a tightly integrated manner. Collectively, TST provides both an organizing framework for identifying and coordinating the different service elements as well as a clinical model that describes exactly what providers do once they are brought together. The four primary service modules within TST include: 1) home- and community-based care; 2) outpatient, skills-based psychotherapy; 3) psychopharmacology; and 4) services advocacy (Saxe et al. 2007). Each service is provided by separate clinicians who are literally "brought to the table" to serve on a multi-specialty TST team as a means to genuinely effect a comprehensive and collaborative treatment.

TST is currently being implemented in 26 programs within 17 agencies across 10 states. Such programs include community-based outpatient programs, child welfare/mental health collaborations, foster care/mental health collaborations, school-based mental health programs, shelters for unaccompanied alien minors, residential programs, pediatric hospitalbased programs, and substance abuse/mental health collaborations. TST has been shown to be effective in several clinical trials (Ellis et al. 2011; Steinberg et al. 2004; Saxe et al. 2005; Saxe et al. 2012) and successfully disseminated in a variety of settings (Hansen and Saxe 2009). Conceptually, the dual emphasis on the emotional/behavioral functioning of the youth and the impact of the social environment makes TST uniquely appropriate to residential settings.

\section{The Adaptation of TST for Residential Settings}

The development of a trauma-informed therapeutic milieuthe unique social environment of youth living in residential facilities - utilizing the TST approach has many positive features, both theoretical and practical. Although TST was originally created as an outpatient and home-based treatment model, providers in several residential settings quickly saw its utility for their programs and worked with the developers to adapt and implement TST to their settings. Over the years, there have been several key features of the adaptation of TST to residential care settings. We describe the most important of these next.

The creation of a common language of care TST helps to create a common language as well as shared goals and values to which all staff members, youth, and families are exposed. For instance, staff members and families are taught to understand that 
what is often referred to as a youth demonstrating "bad", "difficult", or "conduct disordered" behavior is actually a youth in a dysregulated state who is reacting either to reminders of traumatic events or significant environmental stressors. Creating a context in which this kind of shared mutual understanding exists helps to change the very nature of the therapeutic milieu that, in turn, creates the opportunity for outcomes that can truly bring about lasting and meaningful change both in the individual and larger system. As discussed above, a process is conducted whereby frequent ratings of both the youth and the social environment are made. This creates a shared language for all providers, professional and non-professional, which greatly facilitates the integration of care.

One of the most important elements of this common language is a shared approach to assessment and treatment planning which results in the team's capacity to use clinical data to hone in on a small number of "priority problems" that define what all residential care services are meant to treat. Once the priority problems are defined, strategies are developed for how each service of the residential care setting (e.g. clinical, milieu, education) addresses the child's priority problems.

One of the primary assessment tools for identifying priority problems is called the "moment by moment assessment". This assessment tool is meant to explore episodes in which the child has become dysregulated and to look for patterns of contextual stimulation and emotional and behavioral responses. Priority problems are defined as follows: patterns of links between specific environmental signals and dysregulated emotional or behavioral responses. As youth usually enter residential care for significant problems regulating emotion and behavior, the moment by moment assessment helps providers understand how there are often specific regularities in the social context and emotional experience of the episodes that bring the child in to care.

\section{A focus on the social environment of the residential} milieu One important adaptation that has been made to TST for use in residential treatment is the definition of the social environment. When TST was originally developed, the stability of the caregiving environment as well as the larger system of care (e.g., social service agencies, outpatient therapy providers, schools, etc.) was the main focus of assessment. What was not specifically addressed was the fact that youth in residential treatment live within a unique social environment that may itself play a significant role in contributing to traumatic triggers/reminders or significant stressors and thus to the dysregulation of the youth. As an example, a residential program in Westchester County, NY, implementing TST, revised the assessment process to specifically evaluate whether the treatment team (defined as direct care and clinical staff) within the therapeutic milieu is meeting the youth's emotional needs.

Specifically, two types of potential distress or threat were identified for assessment in the milieu. The clearest example is a violation of boundaries. If a staff member verbally or physically threatens or is physically or sexually abusive to a resident, the milieu environment is clearly threatening. Such violations would likely have a negative impact on the entire milieu, in addition to the specific youth being subjected to them, which would thus require immediate administrative intervention. A potentially more subtle and yet more pervasive form of distress within the therapeutic milieu comes in the form of violations of "team integrity". Because residential staff members are, in essence, the youth's immediate caregivers during residential treatment, the functioning of the team as a surrogate family system can have a profound impact on the youth's functioning. If a team does not have good systems for communication among members or if team members do not consistently uphold residence expectations (e.g., morning staff allowing youth to have "seconds" at breakfast, but evening staff not allowing second helpings for dinner even though the administrative rule is that these must always be allowed), the milieu environment is distressed.

Another example would be staff members openly discussing their feelings about other staff or the youth. If such conversations take place in the youth's presence, a more subtle boundary may be violated and the youth may be reminded of dysfunction within her/his primary family system, which may lead to dysregulated emotions and/or behavior. Such violations of team integrity, although often without malicious intent, are ubiquitous within congregate care settings, and are a critical factor to be considered in the care of traumatized youth. Staff members providing care in residential settings are at risk for contributing to the types of environmental distress discussed because of the prevalence of trauma histories in people who tend to seek out such roles in child serving organizations (Bloom and Farragher 2010).

Assessing for distress or threat within the therapeutic milieu of residential programs is one of the most important innovations of TST. Residential-based TST teams now have a system and format for regularly discussing the functioning of the team and ascertaining whether individual team members (or the team as a whole) are effecting a distressed or threatening environment. This process allows the team to develop solutions and proactively identify and address problems in a more productive manner. Adhering to the TST principle of insist on accountability, particularly your own, the team cannot avoid addressing such issues. As an example, a TST team would determine that it is contributing to a distressed environment if the team allowed a given youth to have phone conversations with his mother, even when the team is cognizant that the mother always and openly blames him for child protective services being called and continuously refuses to let him return home. In such a case, the team is not acting to protect the youth by monitoring or suspending calls until the team intervenes with the mother, not providing support to the youth, and not meeting the youth's needs. Hence, the team is central to creating a distressed milieu environment for the youth. Once such an assessment is 
conducted, efforts can be made to find ways to make the milieu more stable.

Family involvement in treatment is an essential component of assessing and addressing the child's social environment. While rating the social environment, for example, the team considers whether the youth's caregiver(s) has been able to adequately meet the youth's emotional needs (i.e., prevent the child from becoming dysregulated or help her/him sufficiently if dysregulation does indeed occur). For many youth in residential treatment, this question is clearly a relevant one as the youth may have phone contact or visits with the caregiver(s). A caregiver who fails to provide agreed-upon calls or visits is rated as not meeting the needs of the youth, thus the environment is considered to be distressed.

If, however, a caregiver does call and/or visit as planned, the environment may still be rated as being less-than-stable. For example, if a caregiver does call, but says something upsetting to the youth during the conversation, the environment may be rated as distressed. If a youth while on a home visit is exposed to violence or not provided with adequate food, for example, the home environment may be rated as threatening.

Residential staff using TST has been trained to engage caregivers by utilizing the TST "Ready-Set-Go" module. This process involves aligning with caregivers by helping them identify and communicate what is most important in their lives: in TST terminology, their life goals and "major source(s) of pain." This strategy allows the clinician to form a treatment alliance with the caregiver based on the caregiver's own priorities rather than priorities imposed by the clinician. The clinician is trained to elicit the priorities of both the caregiver and youth and to consequently develop a treatment plan that is equally based on their input as well as the assessment conducted by the residential TST team.

TST as a vehicle to integrate care Historically, treatment within residential settings has often followed a "private practice" model wherein each individual clinician provides therapy according to her/his own approach based on her/his own training and experience. While such a model may lead to positive outcomes, this approach does not allow a residential program to provide treatment to all youth based on an agreed-upon clinical model in which all clinicians have been trained. In contrast, TST is a systems-based treatment that can provide a framework agency-wide and across all staff. Although TST is fully documented in a published manual (Saxe et al. 2007), the model is not a "one size fits all" intervention. Rather, TST is a flexible, systemic approach to treatment planning based on frequent reviews of relevant data. As previously mentioned, TST is also an organizational model for systems change.

The decision to adopt and implement a system-wide approach to conceptualizing and implementing trauma-focused, evidencebased practice such as TST requires a commitment from agency leadership to make changes throughout every level of the organization. Part of these changes comes in the form of trainings that typically are directed at social workers, psychologists, and psychiatrists, but not the direct care staff. Such differential training can facilitate splits or exacerbate already-existing splits between the clinical and direct care staff, which unfortunately often contribute to creating a distressed or threatening environment for the youth.

The direct care staff members are the adults who spend the most time with the youth. They are the ones on the "front lines" who most likely intervene when the youth become dysregulated and thus in many ways are in most need of training and support. TST emphasizes the importance of creating a TST team of which direct care staff are a crucial component. The team approach makes clear the need for training to reach all levels of the team while also emphasizing the importance of contributions of all team members. For example, when assessing a youth's present emotional state, the clinician may state that the youth appeared regulated in the most recent session whereas a night staff member might report that the youth cries quietly in bed each night — an important clinical observation that might not come to light without that staff member's input being specifically sought out and valued in a TST team meeting.

A frequent barrier cited in many residential programs is the difficulty of freeing up direct care staff for training and participation in team meetings as these team members are responsible for constantly supervising the youth. This obstacle requires administrators to be creative in creating opportunities for training and for scheduling team meetings. In some cases, financial issues are involved, such as paying overtime to allow staff to come in for training or meetings when they are not scheduled to work. One agency that has successfully adapted and implemented TST in a residential facility solved this dilemma by integrating training into already-existing meetings. This agency observed that once the TST concepts and language became a greater part of daily interactions, meetings, and internal processes, the trainings consequently became more integrated into the milieu itself. Examples of this diffusion of innovation include direct care staff being overheard and observed using the TST concepts in their daily work, such as referring to a youth in crisis as "dysregulated" rather than as "acting up" or "being bad" as might have been the case in the past and examining the milieu to determine the environmental triggers/stressors that might be eliciting the youth's distress.

Other important organizational innovations that may help with successful implementation of TST in residential programs include, but are not limited to, hiring a full-time staff member as a TST coordinator; redefining the role of the lead clinician (e.g., psychologist, social worker) within the milieu to become the TST team leader; creating increased time for treatment planning meetings; and changing job descriptions and performance evaluations to align with TST benchmarks (e.g., adherence to the "10 TST Principles"). Perhaps most important is a relentless focus on examining possible factors within the team and the 
milieu that may be impacting the overall environment, thus contributing to a distressed or threatening environment for all youth. For example, if a significant change has occurred (e.g., a staff member no longer working at the agency) but the youth have not been adequately informed or given the opportunity to process their reactions to this event, the environment may be distressed for all youth and for staff as well. In such a case, an account of the organization's present functioning may be needed to determine how organizational factors may be affecting both staff members and youth. To that end, tools have been developed to assess the functioning of the residential team/ milieu (Appendix B).

\section{Case Example}

In order to best illustrate how TST can be applied in residential care settings we provide the following case example:

"Deshaun" is a 15-year-old boy placed in residential care through the New York City child welfare administration. Deshaun had been removed from his biological mother's custody because of allegations of abuse and neglect, and parental rights have been terminated for both parents. He had several failed foster home placements, and at the time of placement in a residential program had no viable discharge resource. Deshaun had a long history of episodes of severe aggression and had twice been hospitalized for suicide attempts, both of which involved efforts to hang himself and occurred around the time of needing to change foster homes. The current admission to residential care was arranged following an outpatient family session when he expressed suicidal thoughts when his foster mother informed him she asked that he transfer foster homes because "I can't take care of you any more".

Deshaun had a very difficult time adjusting to the residential care setting. His first weeks were marked by noncompliance with program rules, yelling at others, destroying property, and of most concern, making serious suicidal gestures. The team engaged in a careful process of "moment by moment assessment": exploring his most concerning outbursts and noticing a significant pattern. As described above, this type of assessment is a critical process of information gathering within TST in order to identify priority problems, namely, patterns of connections between specific environmental signals and dysregulated emotional or behavioral responses. What were these patterns in Deshaun's case?

The team noted that Deshaun's patterns of suicidal ideation and behavior prior to admission were usually in the context of a transition between foster placements and hypothesized that in a child with such a history of abuse and neglect, the context of being informed about a change in placement may have lead to feelings of abandonment. These feelings, the team surmised, may be the driver of the suicidal behavior. With this hypothesis, the team began to gather data about the episodes of suicidal ideation and behavior expressed since admission. A direct care staff member noted a pattern that Deshaun has become particularly suicidal on Friday afternoons and noted that this was a time of particular difficulty because many of Deshaun's peers would leave the milieu to go on weekend home visits beginning on Friday afternoon. Another direct care staff recalled several conversations with Deshaun on Friday afternoons when he would express resentment that the peers "had a home to go to...unlike me".

The team then decided to gather information about Deshaun's experience on Friday afternoon and, indeed, determined that the experience of others leaving the unit to be with family on Friday afternoons led to feelings of abandonment and aloneness which prompted suicidal behavior. This experience was highly consistent with the context of Deshaun's suicide attempts prior to admission. The team then constructed a treatment plan for Deshaun, based on this priority problem. The team, knowing that weekends are particularly difficult for him as he sees other residents going on home visits, put into place a plan in which extra staffing was arranged specifically for Deshaun starting on Friday afternoons. This consisted of a staff member with whom he had a good relationship spending time with him doing a pleasurable activity, during the time the other youth were leaving for home visits.

The team also made sure his weekends were tightly scheduled, to keep him busy and engaged in activities he liked. A treatment plan that proactively inserted experiences of caring relationships at precisely the times when he was most likely to feel alone and abandoned, was instrumental in diminishing his urge to harm himself. Further, the treatment plan integrated emotional regulation skills sessions to help Deshaun have increased capacity to manage the emotion of loss and abandonment so that he had options other than to feel suicidal. Accordingly, this intervention approach addressed both components of the trauma system:

1. The child's limited capacity to regulate emotion when experiencing signals suggesting loss and abandonment by building emotional regulation skills in the face of these signals; and

2. The social environment's limited capacity for helping the child to regulate emotion and to protect the child from triggering stimuli by organizing care around Deshaun's most vulnerable moments (when he is reminded of loss and abandonment).

As Deshaun began to have greater capacity to regulate emotion when reminded of loss and abandonment, and these signals became less ubiquitous in his social environment, his suicidality dramatically reduced, he became much more engaged in the program, and he required much less intensive staffing. Simultaneously, the team focused on the "Services Advocacy" treatment module of TST, designed to address his 
lack of a stable plan for his future. While his permanency plan was adoption, there was no viable discharge plan for him, which in itself represented a significant signal of abandonment for Deshaun. Therefore, the team actively engaged in developing a discharge plan for him, including him in the process. This required legal advocacy with a child welfare attorney as well. As Deshaun became more aware of the team's efforts to help him move on to the next level of care, he was able to use his newfound emotional coping skills to tolerate the process of waiting for this to occur.

\section{Outcomes for TST in Residential Care}

TST has been implemented in three residential programs and different sets of outcomes have been tracked in each. The first implementation of TST in residential care was in the Boston Intensive Residential Treatment Program (Boston IRTP) where TST was used as a restraint reduction program and data on use of restraint was tracked carefully. The second implementation of TST was at Children's Village in Dobbs Ferry, New York,that collected data related to the quality of care of individual cases. The third implementation of TST in residential care was at KVC Residential Services in Kansas City, Kansas, where a more complete program evaluation has been implemented. We describe each of these programs in turn:

\section{Boston Intensive Residential Treatment Program (BOSTON IRTP)}

The Boston IRTP is a 20 bed residential treatment center funded by the Massachusetts Department of Mental Health (DMH) to Boston Medical Center in 2000. IRTP's are a core part of the Massachusetts DMH child services program to provide intensive, long term treatment to children and adolescents who have severe and treatment refractory psychiatric disorders. Most residents have had repeated unsuccessful inpatient and residential care treatment before they are admitted to an IRTP setting. The contract was awarded to Boston Medical Center in July, 2000, and an early version of TST was implemented at the Boston IRTP beginning in September, 2000. The TST program was initially implemented as a restraint reduction program and so data will be presented on the use of restraints once TST was implemented.

Data is presented on the use of physical restraints on the Boston IRTP between September, 2000 (when TST was initiated), and December, 2007 (see Fig. 1). This figure also includes data on staff and child injury over this time course. As can be seen, a dramatic and sustained reduction in use of physical restraints followed the implementation of TST. Importantly, restraint reduction was not accompanied by an increase in staff or child assaults.

\section{The Children's Village}

The Children's Village (CV), Dobbs Ferry, N.Y., was founded in 1851 to shelter New York City's immigrant adolescents who committed petty crimes. CV's campus in Dobbs Ferry provides short-term residential care for more than 1,200 youth per year. The care of children and families addresses diverse needs such as permanency, mental illness, behavioral problems, homelessness, education, domestic violence, substance abuse, life skills training, housing, education, and employment. Children's Village, recognizing the need to address the traumatic history of the youth they serve, sought out a trauma model, and entered into a consulting relationship with Dr. Saxe in 2007, to implement TST. The Children's Village TST program was initially piloted in two residential cottages over 1 year and then the program was brought to scale as the primary treatment model for all 15 residential cottages.

The Children's Village TST Program has not yet implemented a comprehensive program evaluation. They have, however, innovated the use of tracking clinical outcomes over the course of treatment and using this data to improve treatment. This is facilitated by their use of the Child Ecology Check in, a nineitem scale developed for TST programs to track changes in the child's emotional regulation capacity and stability of the social environment during the TST program. We present the tracking of outcomes related to the case of Deshaun described above. These outcomes are illustrated in Fig. 2.

As can be seen in Fig. 2, Deshaun's scores on the CECI for a period of time prior to, and after, putting into place the clienttailored TST intervention plan described above. Keeping in mind that higher scores indicate more dysregulation and a less stable environment, it can be seen that the scores for environment and for emotional and behavioral regulation vary together. As the environment becomes more distressed, Deshaun becomes more dysregulated. The intervention designed to stabilize the environment was implemented on January 15, 2008.

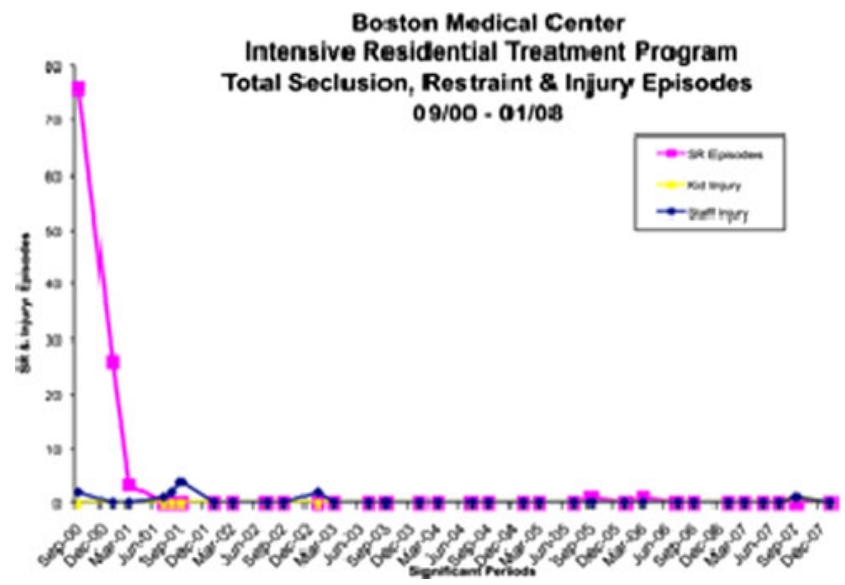

Fig. 1 Numbers of incidents of seclusion and restraint and staff injury in an intensive residential treatment program before and after implementation of Trauma Systems Therapy 


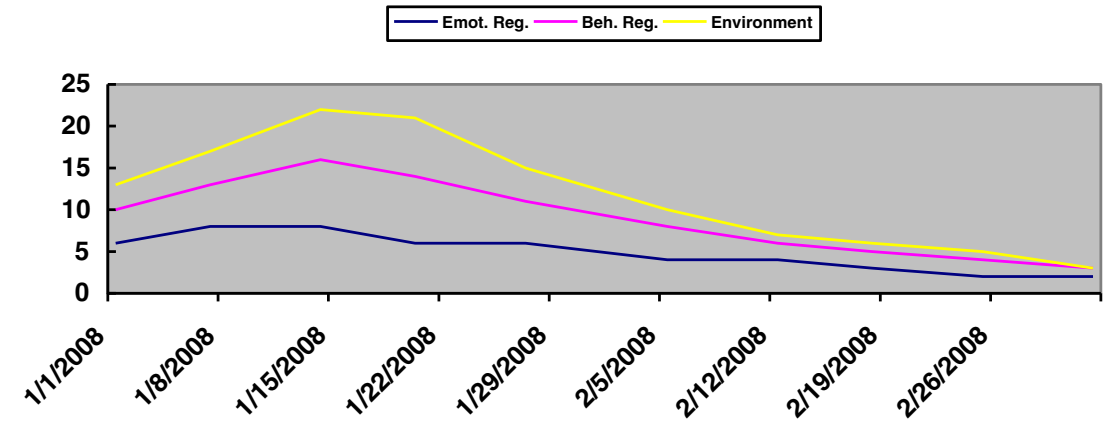

Fig. 2 CECI scores for Deshaun 1/1/08-2/26/08. This graph shows Deshaun's scores on the Child Ecology Check IN (a TST specific measure of emotional/behavioral regulation and stability of the social

environment) for a 9 week period of time. High scores = lower level of functioning (less regulated behavior and emotion, less stable environment

\section{KVC Health Systems, Inc}

KVC Health Systems, Inc, in Lawrence, Kansas, has completed a more conventional program evaluation of TST. KVC provides a continuum of integrated child welfare and mental health services to children and families within an advanced organizational community developed over the past 40 years. KVC offers one of the largest continuums of care in the nation, serving nearly 25,000 children and families daily in Kansas, Nebraska, Missouri, West Virginia and Kentucky. KVC is a lead child welfare contractor in the established Kansas public/private partnership and is in the first year of an outcomes based contract with the State of Nebraska as a result of its recent child welfare reform. KVC has been implementing TST in its residential programs since 2008.

The KVC TST program began as a pilot project with a subpopulation of youth $(n=70)$ in out-of-home care in the Prairie Ridge Psychiatric Residential Treatment Facility in Kansas City. These youth received services in an adolescent boys' residential treatment facility from January 1, 2009, to December 31, 2009. Intake data showed youth were exposed to an average of four traumatic events - the most common being physical abuse, domestic violence, sexual abuse, and exposure to community violence. As identified by the UCLA PTSD Index DSM-IV (Steinberg et al. 2004), $61 \%$ of the total population met criteria for Post Traumatic Stress Disorder, $25 \%$ met partial criteria and $14 \%$ did not meet criteria. At intake, these youth presented with an average score of 144 on the Child and Adolescent Functional Assessment Scale (CAFAS; Hodges 1999), which is consistent with youth needing intensive treatment.

Residential staff and outpatient clinicians received training and consultation from the developers of TST. Case managers and resource/kin providers also received training in TST. The overarching goal of the project was to ensure that youth leaving residential care received the same, consistent, child-specific TST services in the community upon discharge. This unique continuum of care, using TST as a mutually-shared model of intervention, achieved the following outcomes (see Fig. 3): a significant drop in levels of functional impairment as measured by the
CAFAS in all eight domains with an average exit score of 56 by the end of the first year of TST (versus an average exit score of 120 for a pre-TST 2008 comparison group).

Figure 4 indicates placement stability for $89 \%$ of youth discharged to a foster home or kinship placement (versus placement stability of only $48 \%$ for a pre-TST 2008 comparison group); and an average of 1.4 placement moves per child (versus 3.4 placement moves per child for a pre-TST 2008 comparison group). In addition, initial results during the latter half of the year demonstrated significant reductions in the utilization of both seclusions and restraints within the residential program. In sum, the provision of TST across residential and foster/kin placements was associated with protective, stabilizing effects on child and family functioning. Fig. 5

\section{Discussion}

Residential treatment programs in the United States admit approximately 50,000 children per year (Vaughn 2005). This number has steadily increased as long-term psychiatric

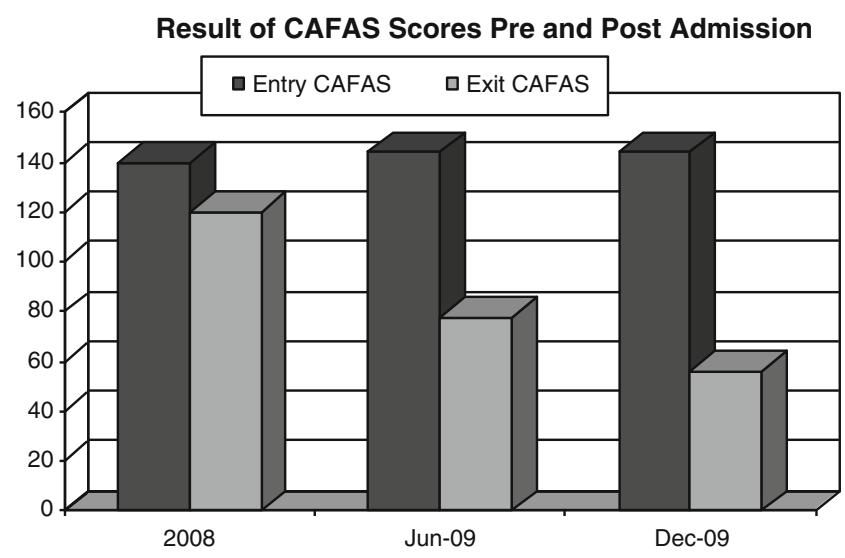

Fig. 3 Scores on the child and adolescent functional assessment scale comparing youth in residential treatment at $\mathrm{KVC}$ receiving TST, as compared to youth who did not receive this intervention 


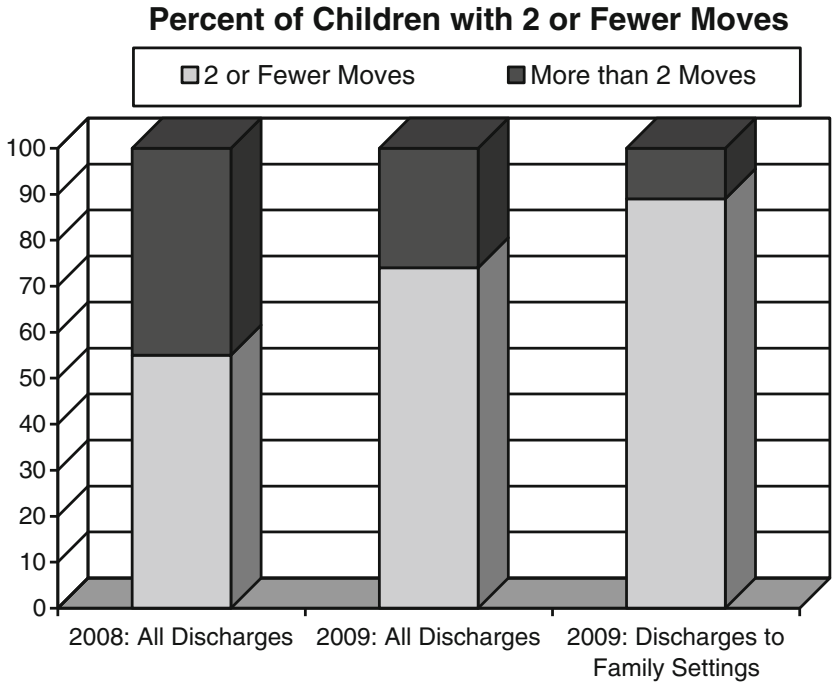

Fig. 4 Number changes in placement for childen in foster care at KVC in 2008 and 2009

hospitals and inpatient institutions have closed (Manderscheid et al. 2001). In addition, many children live in residential facilities because of a shortage of community-based foster homes. Sixty-nine percent of youth admitted to residential care come from child welfare and juvenile justice service systems; these youth present with higher acuity levels and rates of mental and behavioral health disorders than youth in the general population (Stagman and Cooper 2010). Because exposure to interpersonal trauma is seemingly ubiquitous in their histories, trauma-informed, systems-oriented treatment approaches are imperative in residential settings. Simultaneously, concerns over historically long lengths of stay and the high cost of residential care underscore the need for effective and efficient treatment.

To resolve these issues, TST would appear at face value to be a solid match with residential programs given that the model provides both a clinical and organizational framework for addressing the mental health needs of traumatized children and youth. However, our experience with adopting and implementing TST indicates that its successful diffusion necessitates a careful examination and focus on several facets unique to residential settings. Such factors include training staff at all levels (i.e., direct care and clinical staff); reconfiguring staff roles and responsibilities as well as creating new positions; increasing treatment planning time; and sharing TST concepts and language with youth and families. Resistance to change/limited staff buy-in; financial considerations; creation of a genuine multidisciplinary TST team within residential treatment (i.e., direct care, clinical, education and therapeutic recreation; Metzger 2006); and the development of a trusting atmosphere that fosters open discussions of milieu functioning were among the challenges found to hamper successful TST implementation.

As cogently articulated by Bright et al. (2010), interventions provided within residential settings must be sensitive to the needs of both the children and the milieu. Specifically, the successful adaptation and implementation of TST in residential care requires training clinicians within the center itself and creating a therapeutic milieu that is both trauma-informed as well as aligned with the core principles of TST. As a mean towards these ends, establishing an atmosphere of trust and mutual support across direct care staff, clinical staff, and administrators is critical. Our experience suggests that this process is a significant challenge in a setting as complicated as residential care settings, but an ideal to consistently strive toward. We believe that a carefully thought-out plan to implement combined clinical and organizational models such as TST can help to shine a light on such complex issues so as to help move treatment in the right direction on this difficult but potentially rewarding journey towards the ultimate well-being of traumatized children and youth. Moreover, future work is needed to ascertain whether such positive outcomes can be achieved with less cost and shorter lengths of stay.
Fig. 5 Number of safety holds for youth in residential treatment at $\mathrm{KVC}$ prior to and during implementation of Trauma Systems
Safety Hold Rate (per 1000 patient days)

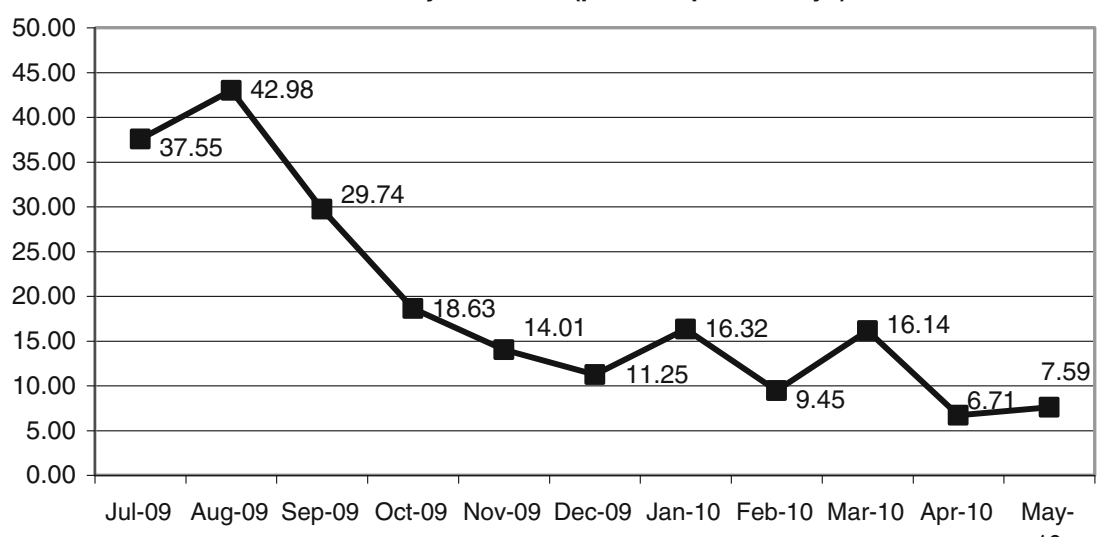


Appendix A. Child Ecology Check In (CECI) - Children's

Village Adaptation

\section{Child Ecology Check In (CECl for TST)}

\begin{tabular}{|c|c|c|c|}
\hline \multicolumn{4}{|c|}{ Name: } \\
\hline \multicolumn{4}{|c|}{ 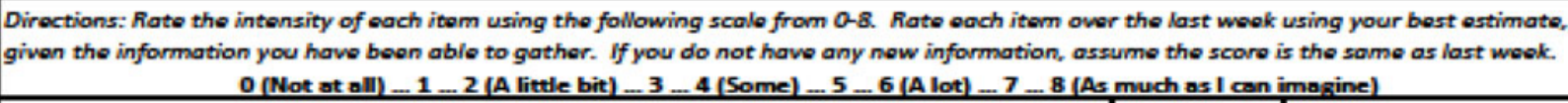 } \\
\hline & & $\mathrm{CV}$ & \\
\hline In the & ie last week... & Rating (0-8) & Comments \\
\hline \multicolumn{4}{|c|}{ EMOTIONAL REGULATION (E) } \\
\hline 1 & $\begin{array}{l}\text {...to what extent has the child been sad or depressed? (Crying, lack of interest in activities, } \\
\text { difficulty concentrating, thoughts of wanting to die, feeling hurt, irritable, numb, or guilty) }\end{array}$ & & \\
\hline 2 & $\begin{array}{l}\text {...to what extent has the child been anxious, worried, nervous, or fearful? (Afraid to } \\
\text { participate in daily activities like school and social events, overly worried) }\end{array}$ & & \\
\hline & ETOTAL & & \\
\hline \multicolumn{4}{|c|}{ BEHAVIORAL REGULATION (B) } \\
\hline$\sqrt[3]{3}$ & $\begin{array}{l}\text {..to what extent has the child's behavior been aggressive, destructive, or harmful towards } \\
\text { others? (Arguing, fighting, stealing, damaging property, physical asgression, verbal } \\
\text { aggression) }\end{array}$ & & \\
\hline 4 & $\begin{array}{l}\text {...to what extent has the child's behavior been harmful, risky, or potentially harmful to him } \\
\text { or herself? (Curtting or injuring self, using substances, being in unsafe situations like driving } \\
\text { under the influence, stayin, out late, going to unsafe neighborhoods or places) }\end{array}$ & & \\
\hline & (2) B TOTAL & $/ 16$ & \\
\hline \multicolumn{4}{|c|}{ TRAUMA (T) } \\
\hline 5 & $\begin{array}{l}\text { to what extent did the child or someone important to him or her experience a situation } \\
\text { that was threatening to his or her safety? (car accident, finding out that someone close } \\
\text { had been badly hurt or put in danger) }\end{array}$ & & \\
\hline 6 & $\begin{array}{l}\text {...did the child experience a situation that reminded him of a past traumstic event? (Seeing } \\
\text { something on TV that was similar to bad events that happened, learning about something } \\
\text { bad happening to someone else) ? If no, skip to (S). }\end{array}$ & Yes or No & \\
\hline & TTOTAL & 18 & \\
\hline \multicolumn{4}{|c|}{ CAREGIVER (C) } \\
\hline & $\begin{array}{l}\text {...to what extent were the child's caregivers (parent's, guardian's, etc.) unable to provide } \\
\text { for his emotional needs? (e.E. not attuned to child's emotional state, ineffective in helping } \\
\text { child to regulate emotion/behavior, disciplinary approach is not appropriate or not } \\
\text { effective). }\end{array}$ & & \\
\hline 8 & $\begin{array}{l}\text {...to what extent was the treatment team (sociotherapy, social work, psychology. } \\
\text { psychiatry, rec) unable to provide for his or her emotional needs? (failure to protect from } \\
\text { aggression or negative stimulation or other inability to provide for child's needs) }\end{array}$ & & \\
\hline & CTOTAL & $\sqrt{16}$ & \\
\hline \multicolumn{4}{|c|}{ SERVICE SYSTEM (S) - 2 - 2 - 2 - 2 } \\
\hline 9 & ...to what extent was the school unable to provide for his or her needs? & & \\
\hline 10 & $\begin{array}{l}\text {...to what extent did the Services System fail to provide effective services that were } \\
\text { needed? (child welfare agencies, medical and mental health prowiders and agencies, courts } \\
\text { were not engaged or were not doing their job effectively). }\end{array}$ & & \\
\hline & STOTAL & $\sqrt{16}$ & \\
\hline & Is youth Fegulated, Emotionally-or Behavionally Dysraguiated? & & \\
\hline & Is enviranment Stable, Distressed, ar Threatening to this youth? & & \\
\hline & What is the Troatment Phase? & & \\
\hline
\end{tabular}




\section{Appendix B-Milieu/Team Check In Form}

This form is designed to help the team take the pulse of the therapeutic milieu itself, including the functioning of the team and the RTC as a community. This information about the social environment is extremely important as it may impact the emotional and behavioral functioning of the youth. Please refer to the information generated by this discussion to help inform the CECI for each youth.

\section{Milieu Functioning (M)}

1. In the past week, have any significant negative events taken place involving the youth in the cottage (physical violence, inappropriate sexual behavior, upsetting news, etc.)?

2. In the past week, have any significant negative events taken place involving staff in the cottage or the larger campus (sudden departures, planned departures, alleged or actual upsetting or inappropriate behavior)?

3. In the past week, have there been any significant programmatic changes within the cottage or the agency (cottages/units closing or moving, school breaks, etc.)?

\section{Team Functioning (T)}

1. In the past week, has the team communicated well together (sharing of important information regarding youth as well as administrative information)?

2. In the past week, has the team followed the 10 TST principles?

3. In the past week, has the team held each other accountable if any violations of the TST principles have occurred?

4 In the past week, has the team supported each other?

Open Access This article is distributed under the terms of the Creative Commons Attribution License which permits any use, distribution, and reproduction in any medium, provided the original author(s) and the source are credited.

\section{References}

Bloom, S. (2005). Creating sanctuary for kids: helping children to heal from violence. Therapeutic community: The International Journal for Therapeutic and Supportive Organizations, 26(1), 57-63.

Bloom, S. L., \& Farragher, B. (2010). Destroying Sanctuary: The crisis in human service delivery systems. New York: Oxford University Press.

Briggs, E. C., Greeson, J. K. P., Layne, C. M., Fairbank, J. A., Knoverek, A. M., \& Pynoos, R. S. (2012). Trauma exposure, psychosocial functioning, and treatment needs of youth in residential care: Preliminary findings from the NCTSN Core Data Set. Journal of Child \& Adolescent Trauma, 5, 1-15.

Bright, C. L., Raghavan, R., Kliethermes, M. D., Juedemann, D., \& Dunn, J. (2010). Collaborative implementation of a sequenced trauma-focused intervention for youth in residential care. Residential Treatment for Children \& Youth, 27(2), 69-79.

Coen, A. S., Libby, A. M., Price, D. A., \& Silverman, K. (2003). Inside the black box: A study of the residential treatment center program of Colorado. Denver: Division of Child Welfare Services, Department of Human Services.
Ellis, B. H., Fogler, J., Hansen, S., Forbes, P., Navalta, C. P., \& Saxe, G. (2011). Trauma systems therapy: 15-month outcomes and the importance of effecting environmental change. Psychological Trauma: Theory, Research, Practice, and Policy. doi:10.1037/a0025192. Advance online publication.

Ford, J. D., \& Hawke, J. (2012). Trauma affect regulation psychoeducation group attendance is associated with reduced disciplinary incidents and sanctions in juvenile detention facilities. Journal of Aggression, Maltreatment, and Trauma, $21,365-384$.

Habib, M., Labruna, V., Newman, J. (2013, this issue). Complex histories and complex presentations: Implementation of a manually-guided group treatment for traumatized adolescents. Journal of Family Violence, 28(7). doi:10.1007/s10896-013-9532-y.

Hansen, S., \& Saxe, G. (2009). Trauma systems therapy: A replication of the model, integrating cognitive behavioral play therapy into child and family treatment. In A. A. Drewes \& A. A. Drewes (Eds.), Blending play therapy with cognitive behavioral therapy: Evidence-based and other effective treatments and techniques (pp. 139-164). Hoboken: John Wiley $\&$ Sons.

Hodgdon, H.B., Kinniburgh, K., Gabowitz, D., Blaustein, M.E., Spinazzola, J. (2013, this issue). Development and implementation of trauma-informed programming in residential schools using the ARC framework. Journal of Family Violence, 28(7). doi:10.1007/s10896-013-9531-z.

Hodges, K. (1999). Child and Adolescent Functional Assessment Scale (CAFAS). In M. E. Maruish (Ed.), The use of psychological testing for treatment planning and outcome assessment (2nd ed., pp. 631664). Mahwah: Lawrence Erlbaum Associates.

Hussey, D., \& Guo, S. (2002). Profile characteristics and behavioral change trajectories of young residential children. Journal of child and Family Studies, 11 (4), 401-410.

Knoverek, A. M., Briggs, E. C., Underwood, L. A., Hartman, R. L. (2013, this issue). Clinical considerations for the treatment of latency age children in residential care. Journal of Family Violence, 28(7). doi:10.1007/s10896-013-9536-7.

Manderscheid, R. W., Atay, J. E., del Hernandez-Cartagena, M. R., Edmond, P. Y., Male, A., Parker, A. C. E., et al. (2001). Highlights of organized mental health services in 1998 and major national and state trends. In R. W. Manderscheid \& M. J. Henderson (Eds.), Mental health. Washington, DC: GPO.

Mayer, M. F., Richman, L. H., \& Balcerzak, E. A. (1978). Group care of children: Crossroads and transitions. New York: Child Welfare League of America.

Metzger, J. (2006). Constructing an integrated and evidence-based model for residential services. Residential Treatment for Children \& Youth, 23(3-4), 163-179.

Noshpitz, J. D. (1962). Notes on the theory of residential treatment. Journal of the American Academy of Child Psychiatry, 1, 284-296.

Rivard, J. C., Bloom, S. L., Abramovitz, R., Pasquale, L. E., Duncan, M., McCorkle, D., et al. (2003). Assessing the implementation and effects of a trauma-focused intervention for youth in residential treatment. Psychiatric Quarterly, 74(2), 137-154.

Saxe, G. N., Ellis, B., Fogler, J., Hansen, S., \& Sorkin, B. (2005). Comprehensive care for traumatized children. Psychiatric Annals, 35(5), 443-448.

Saxe, G. N., Ellis, B., \& Kaplow, J. B. (2007). Collaborative treatment of traumatized children and teens: The trauma systems therapy approach. New York: Guilford Press.

Saxe, G. N., Ellis, B. H., Fogler, J., \& Navalta, C. P. (2012). Innovations in practice: preliminary evidence for effective family engagement in treatment for child traumatic stress: a solutions-oriented approach to preventing dropout. Child \& 
Adolescent Mental Health, 17(1), 58-61. doi:10.1111/j.1475-3588. 2011.00626.x.

Stagman, S. \& Cooper, J. L. (2010). Children's mental health: What every policymaker should know. National Center for Children in Poverty (NCCP) website: www.nccp.org/publications/pdf/text_929.pdf.

Steinberg, A. M., Brymer, M. J., Decker, K. B., \& Pynoos, R. S. (2004). The university of California at Los Angeles posttraumatic stress disorder reaction index. Current Psychiatry Reports, 6, 96-100.
Vaughn, C. F. (2005). Residential treatment centers: not a solution for children with mental health needs. Clearinghouse Review Journal of Poverty Law and Policy, 39(3-4), 274.

Zelechoski, A.D., Sharma, R., Beserra, K., Miguel, J., DeMarco, M., Spinazzola, J. (2013, this issue). Traumatized youth in residential treatment settings: Prevalence, clinical presentation, treatment, and policy implications. Journal of Family Violence, 28(7). doi:10.1007/ s10896-013-9534-9. 